1 Universidade de São Paulo (USP) - São Paulo (SP) Brasil.

beth.araujolima@gmail.com

2 Universidade Estadual Paulista (Unesp) - Assis (SP), Brasil.

\section{Práticas estéticas e corporais: criação e produção de subjetividade na atenção psicossocial}

\author{
Aesthetic and body practices: creation and production of subjectivity \\ in psychosocial care
}

Elizabeth Araújo Lima1,2, Guilherme Providello,3, Juliana Araújo Silva $\mathbf{1 , 2}$, Juliana Maria Padovan

Aleixo ${ }^{2}$, Lívia Pellegrini2, Paula Carpinetti Aversa², Tais Barrenha², Tânya Marques Cardoso ${ }^{2}$

DOI: $10.1590 / 0103-1104202112913$

RESUMO Práticas estéticas e corporais têm ocupado um lugar significativo na atenção psicossocial, no contexto da Reforma Psiquiátrica brasileira. Propostas que inventam outras formas de produção de saúde e de subjetividade, associadas à participação social, têm valorizado a diversidade de formas de expressão em saúde mental e a diferença nas formas de existência. Com o intuito de estudar essas práticas e criar um campo de comunicação e produção coletiva de suas singularidades e seu plano comum, um grupo de pesquisadores se reuniu no Programa de Pós-graduação em Psicologia da Universidade Estadual Paulista e desenvolveu pesquisas articuladas ao projeto 'Práticas estéticas e corporais na atenção psicossocial: processos de criação e produção de subjetividade'. Nessas pesquisas, foram exploradas as relações entre arte e saúde mental, a produção das políticas públicas relacionadas ao campo, o desenvolvimento das práticas clínicas, artísticas e culturais e a formulação de conceitos e perspectivas teóricas que sustentem essas práticas. Neste texto, serão apresentadas, brevemente, as políticas públicas de saúde e cultura que foram desenvolvidas no Brasil nos últimos 30 anos, sua articulação intersetorial e algumas experiências práticas nesse campo, que temos desenvolvido e pesquisado.

PALAVRAS-CHAVE Saúde mental. Política pública. Arte. Cultura.

\begin{abstract}
Aesthetic and body practices have played a significant role in psychosocial care, in the context of the Brazilian Psychiatric Reform. Proposals that invent other ways of producing health and subjectivity, associated with social participation, have valued the diversity of expression in mental health and the difference in forms of existence. In order to study these practices and create a field of communication and collective production of their singularities and their common plan, a group of researchers met in the Graduate Program in Psychology at Universidade Estadual Paulista, creating the line of research 'Aesthetic and body practices in the psychosocial care: processes of creation and production of subjectivity'. In the inquiries developed, the relations between art and mental health, the production of public policies related to the field, the development of clinical, artistic and cultural practices and the formulation of concepts and theoretical perspectives that support these practices were explored. In this paper, the health and culture public policies that have been developed in Brazil in the last 30 years, their intersectoral articulation and some practical experiences in this field, which we have developed and researched, will be briefly presented.
\end{abstract}

KEYWORDS Mental health. Public policy. Art. Culture.

${ }^{3}$ Centro Universitário de Ourinhos (Unifio) - São Paulo (SP), Brasil. 
O risco - estou arriscando descobrir terra nova. (Clarice Lispector, em Água Viva)

\section{Introdução}

A atenção psicossocial se configurou como um conjunto de práticas e saberes que orientam a invenção de dispositivos de cuidado em saúde mental no contexto da Reforma Psiquiátrica brasileira ( $\mathrm{RPb})$. Entre esses dispositivos, as práticas estéticas e corporais ganharam relevância, ampliando as possibilidades de atenção em projetos de caráter artístico e cultural. Essa perspectiva começou a ser desenvolvida a partir dos anos 1980, quando movimentos sociais e mobilizações públicas pela democracia provocaram importantes transformações no cenário político do País. A luta pelo fim da ditadura militar, a construção da abertura política e o fortalecimento de diversos movimentos em defesa dos direitos de todos criaram as condições para a promulgação de uma nova Constituição, em 1988, à qual se seguiu a construção de políticas públicas pautadas nas ideias de saúde e cultura como direitos fundamentais.

Essas políticas foram fortalecidas nos últimos 30 anos e encontram-se, hoje, fortemente ameaçadas por uma agenda de retrocessos. Evidencia-se, assim, que a construção das políticas não indica o fim das lutas. É sempre no entroncamento das lutas que se estabelecem formas de produzir e exercer direitos, que só podem ser garantidos no espaço público quando se pertence a uma comunidade no interior da qual é possível agir e participar, segundo Arendt ${ }^{\mathbf{1}}$. Foi para construir esse espaço público que trabalhadores de saúde, cultura e artes e usuários e familiares de serviços públicos se juntaram aos movimentos sociais e abriram um caminho de atuação intersetorial, ressignificando a presença das atividades artísticas e culturais a partir de uma perspectiva ético-estético-política.
Nesse contexto, práticas estéticas e corporais passaram a instigar a invenção de outras formas de produção de saúde e subjetividade, associadas à participação social e à produção cultural. Promovem-se, assim, novas articulações entre as experiências singulares e a vida coletiva, na afirmação dos direitos de fruição e produção cultural e na valorização da multiplicidade de formas de existência e da diversidade de formas de expressão.

Com o intuito de criar um campo de comunicação e investigação coletiva dessas práticas, suas singularidades e seu plano comum, foi criado o projeto 'Práticas estéticas e corporais na atenção psicossocial: processos de criação e produção de subjetividade', na linha de pesquisa 'Atenção psicossocial e políticas públicas' do Programa de Pós-graduação em Psicologia da Universidade Estadual Paulista (Unesp). O projeto articula uma rede de pesquisas que investigam as relações entre arte e saúde mental, a produção das políticas públicas relacionadas ao campo, o desenvolvimento das práticas clínicas, artísticas e culturais e a formulação de conceitos e perspectivas teóricas que sustentem essas práticas ${ }^{2-9}$.

A cartografia é o ethos metodológico que ambienta essas pesquisas, que acompanham processos e que são marcadas por uma atitude crítica de transdisciplinaridade. Essa atitude faz atravessarem-se as disciplinas na construção de um plano composto por materiais e procedimentos heterogêneos - "componentes teóricos e tecnológicos, mas também estéticos, éticos, econômicos, políticos e afetivos"10(74) - na afirmação do caráter construtivo e inventivo da produção de conhecimento. As pesquisas que envolveram seres humanos foram realizadas de acordo com princípios éticos e foram aprovadas pelo Comitê de Ética em Pesquisa da Unesp.

Neste texto, serão apresentadas, brevemente, as políticas públicas de saúde e cultura que foram desenvolvidas no Brasil nos últimos 30 anos, sua articulação intersetorial e algumas experiências nesse campo, que temos desenvolvido e/ou pesquisado. 


\section{A construção de políticas públicas de saúde e cultura}

\section{Reforma Psiquiátrica e atenção psicossocial}

As lutas sociais voltadas à defesa e à promoção da saúde como direito mobilizaram diferentes atores e grupos da sociedade civil em torno de um projeto comum e, através do Movimento da Reforma Sanitária, possibilitaram a criação do Sistema Único de Saúde (SUS), fundado nos princípios de justiça social, equidade, integralidade e universalidade. A proposição do SUS expressa, assim, uma radicalização do projeto democrático, que vai muito além da oferta de serviços de saúde e garantia de acesso e consumo desses serviços, apostando na criação de práticas de saúde comprometidas com a dimensão pública da vida"1.

No contexto da criação do SUS, e influenciada pelas experiências de transformação dos modelos de atenção em saúde mental em diversos países, surge a Luta Antimanicomial. Esse movimento político e social, formado por trabalhadores da saúde mental, familiares e pessoas com sofrimento psíquico, tem lutado pelo fim dos manicômios e das práticas de violência, tortura e maus tratos que são realizadas ali, tendo como um de seus princípios a ideia de que a aproximação à experiência da loucura deveria se dar no espaço cultural.

Um dos resultados da Luta Antimanicomial foi a construção da $\mathrm{RPb}$ como política pública de saúde mental, pautada na estruturação de uma rede de atenção não hospitalocêntrica. $\mathrm{A} \mathrm{RPb}$ foi profundamente influenciada pela Psiquiatria Democrática Italiana, que considerava que os desafios colocados para os profissionais de saúde mental não seriam a cura e a adaptação à vida produtiva, mas a produção de vida, de sentido, de sociabilidade. $\mathrm{Na}$ articulação entre a materialidade do espaço institucional e a potencialidade dos recursos subjetivos, nomeada por Franco Rotelli12 como economia terapêutica, deveria emergir uma comunidade marcada pela solidariedade e pela afetividade. A materialidade do espaço institucional compreende a forma como o serviço se organiza, o tipo de modelo assistencial que o caracteriza, o regime de trabalho e a remuneração do profissional de saúde. Nesse contexto, o deslocamento da noção de cura para a de produção de vida potencializa mudanças subjetivas ao mesmo tempo que promove o desmonte da lógica asilar. Nesse processo de mudança de paradigma, todos os atores são convocados à construção do sentimento de pertencimento e à tessitura dos laços comunitários.

A transmutação dessa proposta em política pública implicou a criação de uma série de diretrizes e portarias que direcionaram a mudança paradigmática, além de alocar recursos para sua implantação, possibilitando o acesso à cultura, ao lazer e à saúde de modo interdisciplinar e intersetorial. A Lei ${ }^{0} 10.216$, de 2001, defende o direito à saúde mental em novos modelos de assistência e é operacionalizada pelas portarias $n^{\circ} 336$ e $\mathrm{n}^{\circ} 189$, de 2002, que instituem os Centros de Atenção Psicossocial (Caps) e possibilitam a abertura dos Centros de Convivência e Cooperativas (Cecco) ou Centros de Convivência e Cultura (Cecc). Nesses estabelecimentos, são realizadas oficinas terapêuticas, artísticas e culturais inscritas na tabela do Sistema de Informações Ambulatoriais do SUS (SIA/SUS), por meio da Portaria $n^{0} 728$, de 2002. Seu conceito é reforçado pelas Conferências Nacionais de Saúde Mental, e na IV Conferência, em 2010, foi reconhecido seu papel na construção da rede intersetorial.

Sua efetivação e transformação em ações de cuidado requerem a superação do paradigma psiquiátrico e implicam, segundo Amarante, uma atuação em quatro dimensões: a dimensão teórico-conceitual, que problematiza teorias e conceitos que sustentam o saber psiquiátrico tradicional; a dimensão técnico-assistencial, relativa aos modos de cuidar; a dimensão jurídico-política, voltada para a discussão e 
redefinição das legislações que envolvem os doentes mentais; e a dimensão sociocultural, que abarca o conjunto de ações que visam a transformar a relação que a sociedade possui com a loucura. A dimensão sociocultural - que busca provocar e desestabilizar o imaginário social relacionado à loucura e envolver a sociedade na discussão da Reforma Psiquiátrica, a partir da produção cultural e artística dos atores sociais envolvidos - é uma das dimensões "mais criativas e reconhecidas, nos âmbitos nacional e internacional, do processo brasileiro de reforma psiquiátrica"13(73).

A articulação dessas quatro dimensões alicerça um novo modo de agir em saúde mental: a atenção psicossocial, que propõe o deslocamento do paradigma psiquiátrico para o paradigma psicossocial, compreendendo o tratamento do sujeito dentro de uma clínica ampliada e transdisciplinar. A atenção psicossocial tem como elemento nuclear a desinstitucionalização, compreendida como um processo de ruptura com o modelo asilar e uma proposta de nova relação com as experiências de sofrimento psíquico, oferecendo tratamento no território, produzindo aproximação entre usuários e comunidade, repensando as condições de cidadania e desenvolvendo ações coletivas para fortalecimento de processos democráticos e construídos com os usuários ${ }^{\mathbf{1 4}}$.

Os aparatos institucionais da $\mathrm{RPb}$ são, antes de tudo, "dispositivos de produção de subjetividade e subjetivação"15(55) que fazem coincidirem as práticas em saúde mental com práticas de produção de subjetividades e de produção de cultura, o que demanda

uma abordagem interdisciplinar, transdisciplinar e intersetorial, com a decorrente construção de uma diversidade de dispositivos territorializados de atenção e de cuidado'6(29).

A desconstrução do modelo manicomial e asilar foi acompanhada, assim, da criação de uma ampla rede de dispositivos de cuidados e produção de subjetividade com foco da assistência no território sociocultural, entre eles, as oficinas, os ateliês e as cooperativas presentes nos Caps e nos Ceccos, como já citado. Várias experiências culturais e artísticas, orientadas pelo paradigma psicossocial, começaram a ser gestadas e implementadas, ampliando a atenção em saúde mental com propostas para assegurar oportunidades de acesso, exercício e expressão dos potenciais criativos, artísticos, culturais e intelectuais.

A saúde mental passou a ser vista na sua relação com o viver, a convivência e as experiências culturais. Concebendo a vida como movimento, assegurar a liberdade desse movimento e sua sustentação seria criar condições favoráveis para a invenção de múltiplas saúdes possíveis ${ }^{17}$.

\section{Cultura como direito e diversidade cultural}

No mesmo período em que ocorreram avanços na direção de uma atenção ampliada em saúde mental, uma alteração significativa nas políticas culturais desencadeou um processo de democratização da cultura, valorização da diversidade cultural e incentivo, por parte do Estado, a iniciativas que emergem em diferentes regiões do País. Questões de subjetividade, território, acessibilidade e diferença passaram a compor as pautas de políticas culturais que concebem a cultura como direito e importante elemento para o desenvolvimento e para a redução da pobreza e da desigualdade.

Lima e Ortellado argumentam que as políticas culturais do período deslocaram o foco da democratização do acesso aos produtos culturais para dar suporte, fomento e acesso às atividades de produção cultural e ao processo criativo aí envolvido, na direção de uma efetiva democracia cultural. Segundo os autores, a atividade cultural gera produtos ou serviços, mas sua verdadeira riqueza está no processo que se realiza num tempo estendido, e envolve esforços constantes de criação, pesquisa e formação ${ }^{18}$.

Um conceito ampliado de cultura orienta essas novas políticas, nas quais as manifestações culturais ganham em diversidade, 
linguagens e funções sociais. A cultura passa a ser vista como experiência comum, vinculada à produção de sentidos e valores e expressão da multiplicidade de formas de vida presente em uma determinada sociedade ${ }^{19}$. Em consonância, as políticas culturais voltam-se a segmentos considerados mais vulneráveis, e passam a incluir em sua agenda a cultura popular, a cultura indígena, das comunidades quilombolas, do povo cigano; voltam-se, também, para a expressão artística de pessoas em sofrimento psíquico e das pessoas com deficiência, valorizando suas expressões artístico-culturais no que estas têm de diversidade e singularidade. Cultura e saúde começam a se imbricar.

\section{Saúde e cultura: intersetorialidade}

A partir de 2003, uma série de iniciativas intersetoriais começa a ser desenvolvida entre o Ministério da Cultura e o Ministério da Saúde. Um exemplo dessas iniciativas foi a realização da Oficina 'Loucos pela Diversidade - da diversidade da loucura à identidade da cultura', que, em 2007, congregou artistas, produtores culturais, profissionais da saúde, pesquisadores e usuários de serviços de saúde mental comprometidos com o desenvolvimento de projetos artístico-culturais no campo da saúde mental20. A ela seguiu-se o Prêmio 'Loucos pela Diversidade', que, em 2009, premiou projetos artísticos desenvolvidos por pessoas em sofrimento psíquico, por grupos autônomos ligados à experiência em saúde mental ou por equipes de instituições e equipamentos de saúde ou cultura.

Os pontos de confluência do conjunto de experiências que se apresentaram a esse prêmio, vindas de setores da cultura e/ou da saúde, foram: a afirmação da saúde e da cultura como direito; a ideia de que práticas culturais podem produzir saúde, e práticas no campo da saúde podem produzir arte e cultura; e a aposta de que experimentações artísticas e culturais com sujeitos que vivem ou viveram experiências de sofrimento e medicalização podem alterar padrões de discriminação e estigmatização, ampliar territórios de circulação e troca, produzir novos sentidos para o sofrimento, criar novas linguagens e expressões culturais e produzir uma vida mais rica para todos ${ }^{21}$.

Para Yasui22, produzir a intersetorialidade implica

construir um processo que envolve um intenso diálogo, que pressupõe reconhecer e respeitar as especificidades e as diversidades de cada campo; explicitar os conflitos e os interesses envolvidos, para que se possam negociar e pactuar ações; unir potências, produzir encontros ao redor dos temas que perpassem por todos esses campos, a saber: a melhoria da qualidade de vida, a inclusão social e a construção da cidadania da população22(155).

Esse desejo de intersetorialidade recoloca o papel das políticas públicas como potencializadoras da força criativa existente em todos e qualquer um, especialmente nas áreas de maior vulnerabilidade e risco social, apoiando-se sobre os eixos da criação, expressão, acesso, difusão, participação e produção de subjetividade. Trata-se, principalmente, de revigorar a dimensão pública das políticas, reconhecendo o protagonismo da criação de políticas no âmbito dos coletivos e dos espaços públicos plurais ${ }^{23}$. Público aqui não é aquilo que é estatal, mas se refere ao espaço no qual se está entre os seres humanos como seres políticos, isto é, o espaço no qual as pessoas podem exercer sua potência de agir.

\section{Experimentações no território vivo das cidades}

As práticas em saúde mental no paradigma psicossocial buscam desconstruir os manicômios, substituí-los por novas instituições que se expandem e se movimentam na relação com outros setores. Essas ações pedem a exploração de um mundo extramuros que anseia pelo trabalho territorial e por uma clínica peripatética ${ }^{24}$. 
O paradigma psicossocial propõe a potencialização dos recursos que o próprio território oferece para cuidar em liberdade, incentivando as trocas, as relações interpessoais, a participação sociocultural, numa rede que sustente desestabilizações para que a vida possa seguir seu curso e suas errâncias. Essa rede é composta por diversos dispositivos, programas e serviços de saúde e cultura, iniciativas da sociedade civil e de grupos autônomos. Juntas, essas iniciativas buscam criar as condições para um acompanhamento efetivo no território vivo da cidade, que envolve elementos materiais e imateriais do lugar: ruas, casas, relações interpessoais, afetos, memórias, histórias e universo cultural, num jogo de territorialização, desterritorialização e reterritorialização ${ }^{25}$.

No âmbito das ações que articulam arte, saúde e cultura, as chamadas 'oficinas' ganharam destaque, introduzindo nos serviços de saúde mental diversos campos de atividades: artesanais, artísticas, esportivas, produtivas e educacionais. $\mathrm{O}$ intuito desses dispositivos é instaurar espaços grupais de socialização, expressão e participação, funcionando como ambiente de convivência e cuidado, de modo a romper com ações iatrogênicas do modelo asilar e desestabilizar enquadres da clínica tradicional5.

A seguir, serão apresentadas algumas experimentações que se deram num ambiente intersetorial e que foram estudadas nas pesquisas que realizamos. Nelas, a produção de saúde e subjetividade implicou o desenvolvimento de "processos de criação voltados para construção de novas línguas, novos territórios, novos sentidos"25(599).

\section{Uma Oficina de Artes Visuais: inventando relações}

Experimentações em artes visuais no âmbito da Reforma Psiquiátrica acontecem em muitos Caps, Ceccos e instituições culturais, abertas aos interessados em diferentes modalidades artísticas, constituindo espaços do comum nos quais predomina a heterogeneidade.
Uma oficina de artes plásticas ocorrida no ano de 2016, na periferia de uma cidade do interior de Minas Gerais, ilustra a potência desses dispositivos, que se constituem como laboratórios, nos quais modos de ser e de estar no mundo podem ser explorados e ganhar expressão através da oferta de materiais, técnicas e repertórios artísticos. Essa oficina se desenvolveu em encontros semanais em um Centro de Esporte e Cultura Unificado, contou com a ajuda do Centro de Referência da Assistência Social (Cras) da região e constituiu, para seus participantes, um território de existência. As experimentações que aí tiveram lugar dialogavam diretamente com a arte contemporânea, na medida em que esta tem explorado e borrado deliberadamente os limites entre vida e arte, dando margem para que a vida se torne estética e a arte se torne viva ${ }^{3}$.

No contexto desse borramento, muitos artistas contemporâneos têm explorado fortemente aquilo que Nicolas Bourriaud denominou estética relacional26: um regime de encontro casual intensivo que coloca a arte no horizonte das trocas humanas e do seu contexto social, acentuando sua prerrogativa de gerar relações inusitadas com o mundo. As estéticas relacionais produzem configurações artísticas coletivas cujo fundamento é dado pela intersubjetividade e que têm como questão central o 'estar-junto' e a criação de redes de conexão, colocando em relevo situações por vezes modestas ou cotidianas, paisagens e situações obstruídas, silenciadas ou apartadas. Partindo do mote da coabitação, essas propostas colocam em questão as formas rígidas e padronizadas de relações humanas, dando passagem a novas formas de se relacionar, de amar, de viver. São lugares onde se elaboram sociabilidades alternativas e momentos de convívio construídos, produzindo espaços-tempo relacionais que tentam se libertar das restrições da comunicação de massa.

Desta forma, a arte contemporânea contribui para que as singularidades possam coabitar um mundo comum, evidenciando uma sintonia preciosa com as propostas antimanicomiais. 
Do material que tece a vida - o prosaico, o cotidiano e o imprevisto -, as artes plásticas encontram meios de expressão, em exercícios de colaboração coletiva, instaurando um estado de participação com o mundo. Como afirma Bourriaud 26(51) "é só, mas é muito". A partir de pequenos gestos, utilizando poucos recursos, muitas vezes precários, a arte volta-se à tarefa de "recosturar pacientemente o tecido das relações".

$\mathrm{Na}$ oficina de artes plásticas, contando com o que tínhamos - sobretudo, conosco, nossos corpos e vidas -, realizou-se uma série de encontros nos quais eram produzidos objetos e acontecimentos nas linguagens da colagem, assemblagem ou performance, e tentava-se dar uma forma ao que emergia no grupo. Tendo como referência a estética relacional, pensamos a própria a oficina como obra de arte, na medida em que operava no horizonte da convivência e das interações sociais. Filmes, documentários, roda de conversa, debates, referências artísticas serviram de trampolim para a produção de objetos ou performances artísticas que problematizavam, principalmente, temas como gênero e sexualidade, que emergiam dos encontros, o que levou à criação do 'Coletivo Diversos Muitas'.

Ao oferecer a oficina como território de existência, campo de experiência estética e enlace social, a proposta aproxima práticas artísticas e práticas clínicas, contemplando o que se espera das políticas de atenção psicossociais, reforçando mais uma vez que a atividade artística é um campo privilegiado para a construção de novas subjetividades, de novas formas de estar-junto que sejam potentes, generosas e mais solidárias.

\section{Uma Oficina de Dança do Ventre: dançar o feminino}

No Centro de Convivência Rosa dos Ventos, em Campinas, a equipe desenvolve práticas conectadas às novas formas de produção e de sensibilidades no campo do cuidado. Entre elas, oficinas de artesanato, práticas de yoga, ateliê de artes e um grupo de dança do ventre. Os Centros de Convivência surgiram no decorrer do processo da $\mathrm{RPb}$ e desenvolvem ações que têm como foco a produção de encontros entre os usuários da saúde mental e a comunidade em que vivem, através de oficinas, grupos e ações comunitárias. Trata-se de um equipamento idealizado a partir das diretrizes do SUS e da atenção psicossocial, onde se promovem convivência, pertencimento e grupalidade na relação com o território, com a rede de saúde, com a comunidade, buscando construir relações intersetoriais e fazendo interfaces com ações culturais e artísticas ${ }^{2}$.

O grupo de dança teve início em 2011 e conta atualmente com cerca de 30 participantes. Desde o princípio, reuniram-se ali muitas mulheres, com faixa etária diversa, chegando de lugares e caminhos muito diferentes. Avós vinham com suas netas e filhas, procurando o grupo espontaneamente; adolescentes chegavam por indicação de outras meninas; mulheres eram encaminhadas ao grupo pelas equipes dos Centros de Saúde, dos Centros de Atenção Psicossocial, do Ambulatório de Transtornos Alimentares, do Centro de Referência à Mulher Vítima de Violência. E assim elas vêm chegando e indicando o espaço da dança para outras mulheres.

O trabalho desenvolvido compõe movimentos tradicionais da dança oriental árabe com alongamento, movimentos de improvisação, práticas de consciência e expressão corporal alinhados a abordagens da Técnica Klauss Vianna, criando espaços para que o grupo possa construir uma linguagem corporal singular a partir da escuta do corpo e da pesquisa e investigação do movimento.

Ao longo desses anos, partilhamos trabalhos cênicos-artísticos, experiências estéticas, transitamos em eventos no circuito da saúde e adentramos o universo da dança, da arte e da cultura de Campinas. São vivências que ampliam o repertório de experiências das mulheres, fortalecendo a grupalidade e construindo outros lugares e outras formas de poder levar a vida, potencializando-a, intensificando-a. 
O foco do trabalho não é exclusivamente terapêutico, artístico, pedagógico ou de socialização. O dispositivo é experimentado em seu caráter híbrido, de modo que o universo das artes, do cuidado e da promoção de saúde se transversaliza, borrando fronteiras e criando espaços de intercessão na produção de encontros.

Para dançar em apresentações e eventos é necessária a preparação dos corpos e a construção de personagens. As mulheres se arrumam juntas, atentas à maquiagem, aos cabelos, ao figurino, aos acessórios. Desviando dos lugares cristalizados do dia a dia, transportam-se a outros universos, conectam-se a outras formas de expressão e linguagem e acessam o feminino, tão invadido e devastado na atualidade. São muitas Marias: Maria-mulher-trabalhadoradançarina; Maria-mulher-mãe que também dança; Maria-mulher marcada por perdas e sofrimento; muitas Marias com marcas que rotulam e que, ao dançar, deslocam-se, inaugurando novos territórios existenciais.

Não se trata de terapeutizar a cultura em tempos de grande patologização da vida. Trata-se de possibilitar a experimentação de formas intensivas de vida. Colocar o corpo em outros movimentos, em experimentação nas linguagens expressivas, em novas direções, para disparar processos de subjetivação.

Falar do grupo de dança do Centro de Convivência Rosa dos Ventos nos faz compartilhar testemunhos de vidas que se expandiram e se deslocaram do senso normativo pautado numa saúde ideal. É preciso pensar e exercitar uma outra saúde que nos aproxime dos processos expressivos como fonte de potencialização da vida. Uma saúde frágil27, que, exatamente por sua fragilidade, intensifica-se nas linhas de vida, agarrando-se às potências.

\section{Uma Oficina de Teatro: experiências de travessia}

Os corpos estão em travessia. Os estados estão em constante mutação, pois estão em plano de experimentação, partindo de um território conhecido para embarcar em uma viagem afetiva:
[...] não se trata de privilegiar o corpo sobre o espírito: trata-se sim, de adquirir um conhecimento das potências do corpo para descobrir paralelamente as potências do espírito que escapam à consciência28(77).

Ao se encontrarem, os corpos afetam e são afetados, atraem-se ou se repelem. O corpo vibrátil, imperceptível, é ativado, e o corpo organismo alcança um outro estado de atenção. E, assim, na composição desse encontro, um plano de consistência é traçado, delineando um território. A geografia é existencial. As sensações marcam o corpo, forjando uma memória afetiva, tecendo cartografias e fazendo emergirem narrativas, como a que segue abaixo.

Inverno. Tarde de sexta-feira azul. O verde da figueira além-muro. Em nosso quintal há de haver sombra e também sol. A oficina inicia-se e estamos todos um tanto desanimados. Lá estão o tecido, delineando a arena, cds, livros, bolinhas. Nice chegou e já se sentou no chão mais inquieta hoje. Silvia anda ao redor observando. Seo Chico já deitado com os pés ao sol, olha absorto o tempo passar. Um silêncio milenar suspende-nos. Eu havia preparado um roteiro de aula mas imersa nessa atmosfera percebi que os corpos pediam chão e ele já estava aquecido para nos receber. Uma largueza estendida. Poder deitar junto... horizontalizar... espreguiçar e em contato com o chão, respirar, deixando o ar entrar e sair, alongando e esticando (o limite é o próprio corpo) mãos, pés, braços, pernas... e logo em seguida relaxar entregando-se ao chão. Soltar sons se o corpo pede voz. Desconfortos, queixas? Silvia para e vira de lado, me aproximo e ela está de olhos fechados como uma criança que se aconchegou. Nice respira, solta a voz fazendo um solilóquio, descrevendo as sensações corporais. Enquanto isso, Seo Chico transcende, merguIhado na temperatura do chão, em seu olhar-menino - silêncio de semente? Introduzo uma música que passa a dar ritmo ao instante e as pessoas iniciam movimentos corporais, 
sempre no tempo-desejo de cada um(a). Com minha voz convido-xs a experimentar modos de caminhar (com pés e mãos, engatinhando, na ponta dos pés, calcanhares, parte interna e externa dos pés) em diferentes velocidades que gradualmente se aceleram e desaceleram. Corpos que ao se encontrar com outros vão dialogando com o movimento, com o olhar, em silêncio de fala. Continuar a mover-se até retornar à posição inicial. Seo Chico levanta-se e senta-se, pernas cruzadas a observar o que acontece. Silvia experimenta os andares e se diverte, de pouco em pouco insinua parar. Nice tem dificuldade de andar mas ela mesma se resolve, não sem reclamar, experimentando intensidades diversas: andando como passarinho, como tigre, como a aranha; galopando, saltando como canguru e enfiando os pés no chão como se de lama fosse. Está concentrada em seu fazer, e vai intensificando os movimentos junto com a expressão vocal em fio contínuo com a expressão do corpo. Nice cresce e contagia todo o grupo a produzir coletivamente. Xs participantes iniciam um diálogo corporal-vocal que se sustenta no tempo enquanto há vontade de interação. Para finalizar a oficina, compartilhamos em roda como foi a experiência para cada um(a). Estamos suando, perguntando se já acabou, se tem lanche agora, levantando, colocando os sapatos.. Nice está sentada e, ainda ressoando a experiência, olha e toca as pernas esticadas. Há um tremor: 'Nossa! Senti, hoje, que tenho perna. Olhem como elas estão? E não por causa do haldol não, é diferente'. Silêncio. Nos olhamos. 'Quem sabe do meu corpo sou eu!'. Ela ri. Todxs rimos $6(75,76)$.

A possibilidade de experimentar o corpo de modo extracotidiano traçou um plano de consistência em que Nice pôde atravessar estados de ir tornando-se. Nadar, boiar, afogar, remar junto. Ao produzir algo singular, esse algo a ultrapassa. (Re)invenções de si e do mundo. A obra em processo inacabado, fazendo-se num Caps no interior de São Paulo.

\section{Uma Oficina de Literatura: a vida ficcionada}

Entre as modalidades de oficina presentes nas experiências da atenção psicossocial, encontramos as oficinas literárias, nas quais se trabalha com formas de expressão através da palavra. Experiências com a literatura oferecem possibilidades de contar as dores e, nesse sentido, forjar ferramentas que ajudem a lidar com o sofrimento. Comunicar essa experiência possibilita produzir marcas e inscrevê-las no mundo. Os relatos e as narrativas potencializam o desejo de arriscar-se a existir muito além do diagnóstico, que, ao se transformar em rótulo, restringe o autorreconhecimento e a autovalorização.

Histórias têm o poder de ensinar, conservar a memória ou alterar o passado; nelas, as vidas são como textos sujeitos à revisão, onde o autor é também o intérprete de si mesmo, o que possibilita uma aproximação à ficção no sentido da permanente reelaboração, da autoinvenção29(1308).

Uma experiência de oficina literária aconteceu em 2012, em uma cidade do interior do Paraná. A proposta buscou proporcionar um espaço de escuta e acolhimento aos usuários do serviço de saúde da cidade, em particular, aos usuários de saúde mental. Num primeiro momento, com o objetivo de esclarecer sobre a proposta, foram organizadas algumas rodas de conversa. Observou-se que os usuários tinham grande dificuldade em entender como esse trabalho poderia contribuir para o tratamento, posto que o atendimento desse serviço era quase que exclusivamente ambulatorial, com consultas mensais e prescrição de medicamento, o que os usuários e familiares consideravam a única e melhor forma de cuidado em saúde.

Para facilitar a chegada dos interessados à oficina, e enfrentar tanto a condição de 'psiquiatrização' que compromete a integralidade do cuidado quanto as dificuldades de locomoção até o serviço, optou-se por flexibilizar o acesso: as oficinas aconteciam em dias 
diversos, na Unidade Básica de Saúde, que funcionava no mesmo prédio do Ambulatório de Saúde Mental, nos horários de funcionamento do serviço. O usuário poderia participar no mesmo dia em que fosse para a consulta.

Nos encontros, eram disponibilizados livros com poesias, alguns textos e material para que os participantes pudessem produzir seus próprios escritos se assim desejassem. A partir dessa proposta disparadora, surgiam, em forma de narrativas, questões pessoais e familiares, troca de experiências, problematização de situações cotidianas e expectativas com relação ao tratamento. Os textos em germinação possibilitavam vislumbrar esboços de vida que se arriscavam a existir.

Nessa experiência, procurou-se pensar as oficinas literárias como ferramenta da clínica em saúde mental. Num contexto em que o cuidado ainda esbarrava em um modelo medicalizador e individualista, pautado na doença, a arte e as produções literárias surgiam como uma forma de transgressão dessa lógica utilitarista.

Pensar a literatura e sua relação com a loucura é pensar na resistência aos discursos que reduzem a subjetividade à identidade; é pensar em processos de singularização. A literatura é a arte de criar ou recriar textos através da escrita e da fala, de forma a transgredir o controle dos corpos e da subjetividade, permitindo certa plasticidade com relação ao mundo habitado pela loucura4 ${ }^{4}$ É através da narrativa (em função de sua aproximação com a ficção) que um movimento de reinvenção é possível, e o grupo, por sua vez, é o espaço onde essa resistência se materializa em uma permanente reelaboração de experiências.

Para Foucault ${ }^{30}$, a resistência não é um processo de cristalização, mas de combate e, sobretudo, de criação de novos modos de ser e de sentir, de transformar situações e de se transformar. Saltar do plano da sintomatologia para o plano da experimentação foi o exercício praticado nos encontros das oficinas. Acontecimento que marca os corpos-pensamentos de quem atravessou e deixou-se ser atravessado pela força intensiva da vida.

\section{Fazendo música e movimento}

A música, no contexto da $\mathrm{RPb}$, aponta para uma diversidade de práticas com formatos, objetivos e métodos distintos. Em uma pesquisa realizada nesse campo, foram identificadas cinco formas principais de se trabalhar com música, organizadas nas categorias: musicoterapia; oficinas sonoras e/ou musicais; bandas, corais, grupos musicais e trabalhos solos; blocos carnavalescos; e experiências de rádios e webrádios ${ }^{5}$.

Entre esses diversos formatos, chamam a atenção os grupos musicais que circulam no cenário da música popular. Em territórios de fronteira, ao habitarem propostas intersetoriais, esses grupos que exploram múltiplos estilos e gêneros musicais aventuram-se numa existência sem vinculações institucionais fixas. Muitos desses grupos tiveram origem em contextos de serviços de saúde e se desvincularam, buscando autonomia e uma inserção nos circuitos artístico-culturais. Seguem, assim, sustentando-se, algumas vezes de forma precária, através de parcerias e cooperações que possibilitam espaço físico para promoverem seus ensaios, conexões com outros atores da saúde e da cultura e participação na formação de estudantes e pesquisadores que desejam se conectar a essas experiências, entre outras possibilidades que alimentam um persistir nesse território híbrido. Exemplos de experiências como essas encontram-se nas trajetórias do Projeto Cidadãos Cantantes e da Banda Lokonaboa, que apresentaremos a seguir.

\section{O PROJETO CIDADÃOS CANTANTES}

Em 1992, surgia o Coral Cênico de Saúde Mental, em forma de oficina aberta, no Centro Cultural São Paulo (CCSP), conjugando produção artística com produção de saúde e subjetividade. Dez anos depois nasceu, ligada a esse projeto, a Oficina de Dança e Expressão Corporal, quando o coral passou a se nomear Projeto Cidadãos Cantantes, compreendendo 
as oficinas de coral e dança e promovendo espaços de singularidade e invenção coletiva ${ }^{8}$.

A Oficina de Coral Cênico trabalha com ritmos, velocidades, ideias e gostos diferentes. Nela, cada voz importa, e cada um cuida um pouco do outro. As relações que se estabelecem na sala de ensaio transbordam-na, produzindo amizades e levando o canto para outros espaços, ao encontro do público. $\mathrm{O}$ trabalho de regência, que foi descrito como um "afinar as diferenças"31(124), busca uma harmonia inusitada no conjunto de tantas vozes diferentes em seus timbres e afinações. Quando o grupo explora uma afinação coletiva, não está à procura da perfeição, que poderia vir a barrar o processo criativo, impondo um crivo à seleção das músicas pela capacidade dos participantes em manter sons agudos e graves. A afinação é construída numa tentativa de compor vozes, ouvir e perceber os timbres de cada um, em um desafio coletivo para produzir uma conexão com os sentidos do que se trabalha nos repertórios. $\mathrm{O}$ incentivo às composições dos próprios participantes é forte, e comumente utilizam-se nos repertórios poesias e letras que surgem ali, numa criação que se faz em muitos. As letras das canções tecem o trabalho com sua força expressiva. Elas são elementos importantes no trabalho do Coral; ao escolhê-las, fazem-se conexões entre sons e enunciados, emergindo uma temática que constitui o eixo do trabalho num determinado momento. As apresentações do coral são acontecimentos que começam no trajeto, quando se dá o aquecimento vocal: o grupo conversa, relembra as letras, canta músicas de repertórios antigos. Antes de entrarem em cena, todos se preparam juntos, compartilhando maquiagens e adereços. Pequenos desajustes saltam na hora da apresentação, mas a resposta do público é sempre muito forte e acolhedora.

A Oficina de Dança e Expressão Corporal (Odec) é um laboratório de movimento e contato de improvisação: os corpos se encontram uns com os outros e consigo mesmos, com as formas que possuem, com suas possibilidades de habitar os espaços, com as sensações que emergem da experimentação. A partir da investigação dos movimentos, é possível uma qualidade de conexão consigo que potencializa o encontro com o outro e ajuda a tecer relações. Explora-se, assim, a potência da dança de promover o exercício de apropriação de si e das possibilidades de transformar-se e de vincular-se. Cada encontro é diferente, tem um clima próprio, uma sequência de músicas particular, uma configuração dada pelas pessoas presentes, uma proposta construída naquele dia. Essas construções poéticas coletivas possibilitam que se entre em estados de jogo com o que está posto no campo social, para que possa surgir uma expressão singular.

Poiéses são atos de tecer sentidos e formar poéticas com matérias diversas, com elementos de um campo coletivo, com os sons e com o corpo. Essas produções coletivas desviantes são, também, atos de resistência, já que através delas experimentam-se corpos, linguagens e sensibilidade que constroem escapes ao uso normativo e capitalista do corpo e às 'formas moldantes', com as quais somos bombardeados cotidianamente nas mídias e nas redes sociais, que veiculam um cuidado com o corpo como vigilância.

\section{A BANDA LOKONABOA}

Outra experiência musical que foi acompanhada em nossas pesquisas foi a da Banda Lokonaboa, uma iniciativa do Projeto de Extensão Universitária 'Atenção Psicossocial na Saúde Coletiva', do Curso de Psicologia da Unesp-Assis. Em sua forma embrionária, a banda foi uma oficina de música oferecida junto ao Caps Ruy de Souza Dias, da cidade de Assis, por estudantes ligados ao projeto de extensão. A oficina foi desenvolvida por vários anos, e o grupo se apresentava em eventos da Luta Antimanicomial ou da Faculdade, até que, em 2002, surgiu a ideia de criar uma banda, que foi um 
desdobramento natural do projeto, dada sua qualidade musical.

Posteriormente, a banda firmou uma parceria com a Pirassis, Associação de trabalhadores, familiares, amigos e usuários da saúde mental da cidade. Em 2009, os ensaios passaram a acontecer no Galpão Cultural de Assis, um espaço compartilhado por vários grupos e Organizações Não Governamentais (ONGs), que havia se tornado um Ponto de Cultura.

Pautada em uma gestão descentralizada e desierarquizada, a banda se servia de uma perspectiva democrática com relação às decisões de figurino, repertório, uso dos recursos e proposta estética. Buscava, assim, introduzir transformações que tocavam, também, os micropoderes, buscando a horizontalização das relações de poder.

O projeto trabalhou sempre com uma perspectiva que se articula diretamente com a dimensão sociocultural da Reforma Psiquiátrica: a produção de um espaço social para a loucura. Para ser possível travar um diálogo entre os ditos sãos e os ditos não sãos,

é necessário antes que a experiência que temos da loucura seja desmistificada, seja deslocada, de modo a permitir que a palavra dos 'não-sãos' tenha aceitação. Seja palavra não mais interdita ${ }^{7(90)}$.

Tal questão pode ser apreendida quando se considera que as apresentações da banda produzem estranhamento e ruptura da perspectiva dos ouvintes, constituindo momentos de reconhecimento cultural das manifestações dos loucos.

Mas a experiência da Banda produz alterações nas paisagens sonoras e sensíveis, principalmente de seus integrantes. A criação de marcas, a apropriação de conteúdo, a reorganização de sensações, que ganham sentidos, tudo isso possibilita a construção de territórios subjetivos, inseridos em uma temporalidade e uma ritmicidade próprias, que encontram um lugar no mundo 32 .

\section{Algumas reflexões para finalizar}

Nos exercícios e experiências que pudemos vislumbrar nos breves relatos acima, artes, cultura e clínica se atravessam, potencializando seus vetores de invenção e conectando os processos de criação à produção de saúde e subjetividade. Esboçar exercícios como esses, que tocam a ação política e a invenção de novas formas de vida e do viver, é uma urgência para todos nós 33 .

São ações que promovem novas articulações entre as experiências singulares e a vida coletiva, tornando possível superar a noção de arte e cultura como recursos terapêuticos, para que possam acessar seu potencial clínico, como experiência estética que dá novos sentidos à vida. Na construção de propostas que restituem a vida na dimensão coletiva e criativa, possibilidades de pertencimento são ampliadas, formas de encontro e convivência são fortalecidas e a participação cultural é intensificada, o que contribui para a efetivação de políticas de caráter verdadeiramente público.

A proposição de políticas públicas e ações intersetoriais coloca em evidência o caráter público e comum das artes, da saúde e da cultura. Trata-se de sedimentar progressivamente uma transversalidade entre processos de subjetivação e processos de constituição do mundo, que têm por referência a produção do comum. Estão em pauta aqui experimentações públicas e coletivas no mundo comum, que comportam a invenção de territórios existenciais, a criação de valores e a constituição de processos de subjetivação, tendo por critério a expansão da vida, e não sua exploração, limitação ou cerceamento. "O Comum não é uma escolha, mas um imperativo da vida humana, em sua requisição radical de relação, de alteridade"23(121).

No momento político atual, em que as políticas governamentais e estatais abandonam os planos coletivo e público, as recentes experimentações nos âmbitos da saúde mental, das 
artes e da cultura que buscaram e buscam de alguma forma abrir-se em direção à dimensão pública que toda política comporta são um patrimônio imaterial de valor inestimável para futuras recomposições mais justas e democráticas da política que virá.

\section{Agradecimentos}

Agradecemos ao Programa de Pós-graduação em Psicologia da Universidade Estadual Paulista (Unesp), Campus Assis, à Coordenação de Aperfeiçoamento de Pessoal de Nível Superior (Capes) e à Fundação de Amparo à Pesquisa do Estado de São Paulo (Fapesp) por todo o apoio que recebemos nos anos em que desenvolvemos nossas pesquisas. Gostaríamos de agradecer também ao Professor Silvio Yasui pela parceria e pelo suporte que nos ofertou no desenvolvimento de nosso projeto de pesquisa.

\section{Colaboradores}

Lima EA (0000-0003-0590-620X)* coordenou a elaboração deste artigo coletivo, organizando o processo, participando da escrita juntamente com os outros autores e realizando a revisão final do texto. Providello G (0000-0001-9069-6571)*, Silva JA (0000-0002-2028-9417)*, Aleixo JMP (0000-0002-7120-7725)*, Pellegrini L (00000002-9867-0621)*, Aversa PC (0000-0002-93481266)*, Barrenha T (0000-0001-6828-4482)* e Cardoso TM (0000-0003-4293-4963)* contribuíram para a elaboração do manuscrito, tendo participado da concepção, escrita do texto e aprovação de sua versão final.

\section{Referências}

1. Arendt H. A condição humana. Rio de Janeiro: Forense Universitária; 2003.

2. Aleixo JMP. Centro de Convivência e Atenção Psicossocial: Invenção e produção de encontros no território da diversidade. [dissertação]. Assis: Universidade Estadual Paulista; 2016. 117 p.

3. Aversa PC. Passagens: encontros em artes, produções de vida. [tese]. Assis: Universidade Estadual Paulista; $2018.170 \mathrm{p}$.

*Orcid (Open Researcher and Contributor ID).
4. Barrenha TS. Escrever para não morrer: Stela do Patrocínio e a literatura como dispositivo de resistên- cia, cuidado e produção de subjetividade. [dissertação]. Universidade Estadual Paulista; 2019. 86 p.

5. Cardoso TM. A que(m) serve a Música na Reforma Psiquiátrica brasileira? Linhas de Audibilidade nas práticas musicais e sonoras da Saúde Mental Coletiva. [dissertação]. Universidade Estadual Paulista; 2014. 184 p.

6. Ferreira LVP. Corpos em travessia: ensaio de uma clínica dos fluxos. [dissertação]. Universidade Estadual Paulista; 2016. 109 p.

7. Providello GGD. Projeto Banda Lokonaboa: criando um 
acorde entre arte, loucura e Reforma Psiquiátrica. [dissertação]. Universidade Estadual Paulista; 2011. 104 p.

8. Silva JA. Poéticas e marginalidades: experiência no Projeto Cidadãos Cantantes. [dissertação]. Universidade Estadual Paulista; 2012. 212 p.

9. Cardoso TM. Tem barulho nesse emaranhado: ensaios sobre música, poder e subjetividade e proposição das linhas de audibilidade para análise de dispositivos sonoro-musicais. [tese]. Assis: Universidade Estadual Paulista; 2020. 185 p.

10. Passos E, Barros RB. A construção do plano da clínica e o conceito de transdisciplinaridade. Psic.: Teor. e Pesq. 2000; 16(1):71-79.

11. Barros RB, Passos E. A humanização como dimensão pública das políticas de saúde. Ciênc. Saúde Colet. 2005; 10(3):561-571.

12. Rotelli F. Desinstitucionalização. São Paulo: Hucitec; 2001.

13. Amarante P. Saúde mental e atenção psicossocial. 4. ed. Rio de Janeiro: Fiocruz; 2013.

14. Costa-Rosa A, Luzio CA, Yasui S. Atenção Psicossocial: rumo a um novo paradigma na Saúde Mental Coletiva. In: Amarante PA, organizador. Archivos de Saúde Mental e Atenção Psicossocial. Rio de Janeiro: NAU; 2003. p. 13-44.

15. Costa-Rosa A. Atenção Psicossocial além da Reforma Psiquiátrica. São Paulo: Editora UNESP; 2013.

16. Costa-Rosa A, Yasui S. A Estratégia Atenção Psicossocial: desafio na prática dos novos dispositivos de Saúde Mental. Saúde debate. 2008; $32(78 / 79 / 80): 27-37$

17. Lima EMFA. A Saúde Mental nos caminhos da Terapia Ocupacional. Mundo saúde. 2006; 30(1):117-122.

18. Lima L, Ortellado P. Da compra de produtos e serviços culturais ao direito de produzir cultura. Dados. 2013; 56(2):351-382.
19. United Nations Educational, Scientific and Cultural Organization. The General Conference of the United Nations Educational, Scientific and Cultural Organization. The 2005 Convention on the Protection and Promotion of the Diversity of Cultural Expressions. Paris, 2005. [acesso em 2020 jan 30]. Disponível em: https://en.unesco.org/creativity/sites/creativity/files/passeport-convention2005-web2.pdf.

20. Brasil. Ministério da Cultura. Loucos pela Diversidade: da diversidade da loucura à identidade da cultura. Relatório Final. Oficina Nacional de Indicação de Políticas Públicas Culturais para pessoas em sofrimento mental e em situações de risco social. Rio de Janeiro: LAPS; 2008.

21. Amarante P, Torres EHG. Loucura e Diversidade Cultural: inovação e ruptura nas experiências de Arte e Cultura da Reforma Psiquiátrica e do campo da Saúde Mental no Brasil. Interface. 2017; 21(63):763-774.

22. Yasui S. Rupturas e encontros: desafios da Reforma Psiquiátrica Brasileira. Rio de Janeiro: Fiocruz; 2010.

23. Guizard F, Cavalcanti F. Por um mundo democrático produzido democraticamente. Lugar Comum. 2009; 27(1):103-123.

24. Lancetti A. Clínica Peripatética. São Paulo: Hucitec; 2008.

25. Lima EMFA, Yasui S. Territórios e Sentidos: espaço, cultura, subjetividade e cuidado na Atenção Psicossocial. Saúde debate. 2014; 38(107): 593-606.

26. Bourriaud N. Estética Relacional. São Paulo: Martins Fontes; 2009.

27. Deleuze G. Conversações. São Paulo: Editora 34; 2010.

28. Deleuze G. Filosofia Prática. São Paulo: Escuta, 2002.

29. Meneguel SN, Moraes SCC. Oficinas de pontos e narrativas: produções discursivas de cuidado em um Centro de Atenção Psicossocial (CAPS). Rev. Mal-Estar Subj. 2009; 9(4):1303-1322. 
30. Foucault M. A ética do cuidado de si como prática da liberdade. In: Foucault M. Ética, sexualidade, política. Ditos e Escritos V. Rio de Janeiro: Forense Universitária; 2004.

31. Maluf JCG. Afinando diferenças: o processo de construção artística do Coral Cênico Cidadãos Cantantes. [dissertação]. São Paulo: Universidade Estadual Paulista; $2005.331 \mathrm{p}$.

32. Providello GGD. Música e subjetividade: experimentações híbridas do pensamento. [tese]. Assis: Universidade Estadual Paulista Júlio de Mesquita Filho; 2018. $100 \mathrm{p}$
33. Lima EMFA. Explorando arte e corpo em um campo expandido: Uma experiência de produção de comum. Ilinx Revista Lume. 2017; 12(3):8-90.

Recebido em 03/03/2020

Aprovado em 18/08/2020

Conflito de interesses: inexistente

Suporte financeiro: Coordenação de Aperfeiçoamento de Pessoal de Nível Superior (Capes) - Códigos de Financiamento 001

(uma bolsa de mestrado e duas de doutorado no País, uma delas beneficiada com doutorado-sanduíche); Coordenação de Aperfeiçoamento de Pessoal de Nível Superior (Capes) Processo no 1750406 (bolsa de doutorado no país); Fundação de Amparo à Pesquisa do Estado de São Paulo (Fapesp) - processo 2011/16633-7 (bolsa de mestrado no País) 